\title{
Case of cerebrotendinous xanthomatosis. I: Unusual ophthalmic features
}

\author{
S J MORGAN,' P McKENNA, ${ }^{2}$ AND R C BOSANQUET ${ }^{1}$
}

From the 'Department of Ophthalmology, Newcastle General Hospital, Westgate Road, Newcastle upon Tyne, and 'Department of Clinical Biochemistry, Royal Victoria Infirmary, Queen Victoria Road, Newcastle upon Tyne

SUMMARY A case of cerebrotendinous xanthomatosis is reported. In addition to the classical ophthalmic and systemic features the patient presented with unilateral proptosis. This feature has never previously been reported. The results of investigations are described and illustrated.

Cerebrotendinous xanthomatosis (CTX) is a rare metabolic disease of autosomal recessive inheritance.' As a result of a defect in bile acid synthesis there is an accumulation of cholestanol, the 5-dihydro derivative of cholesterol, in serum and tissues. ${ }^{23}$

The clinical signs include bulky tendon xanthomata, neurological dysfunction, spinal cord paresis, premature coronary atheroma, and early onset cataracts. ${ }^{+}$There are indications that some of the more serious neurological manifestations are reversible with treatment. ${ }^{56}$

This report is only the second in literature of the $\mathrm{UK}^{\top}$ and describes a new ophthalmic symptom proptosis due to orbital involvement. From our experience CTX may occasionally go unrecognised.

\section{Case report}

A 42-year-old single unemployed labourer presented in February 1986 complaining of deteriorating vision. His vision was said to have always been poor. His optician reported a best corrected acuity of $6 / 18$ in each eye at age 21 , when he was first prescribed spectacles. In 1979 and 1981 tendon lumps had been excised (notes not traceable). The family history was negative for xanthomata, hyperlipidaemia, and consanguinity.

On general examination he was of short stature with brachydactyly and dolichocephaly, and had

Correspondence to Mr S J Morgan, FRCSEd. Southampton Eye Hospital, Wilton Avenue. Southampton SO9 4XW.

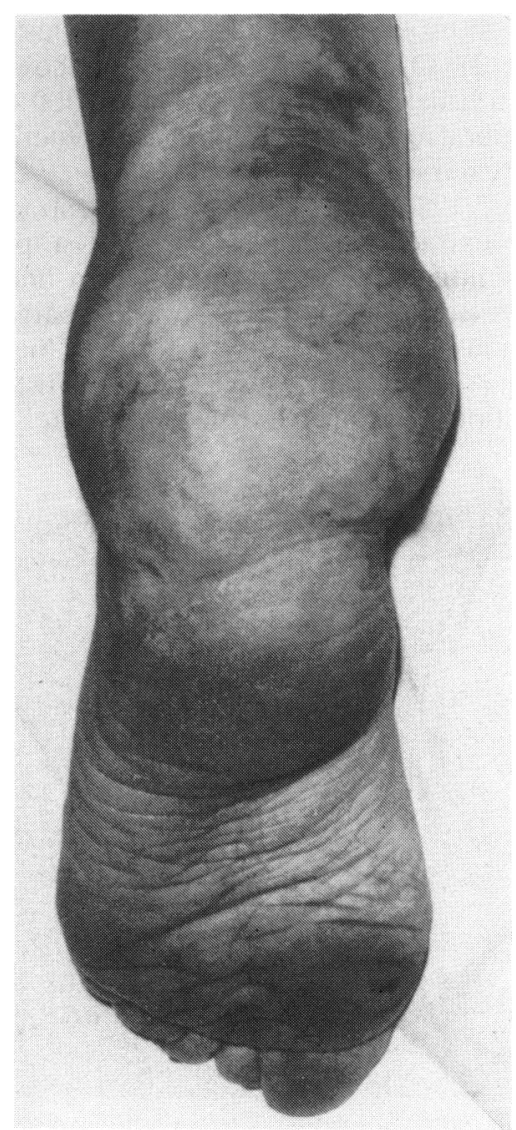

Fig. 1 Bulky xanthoma of left Achilles tendon. 


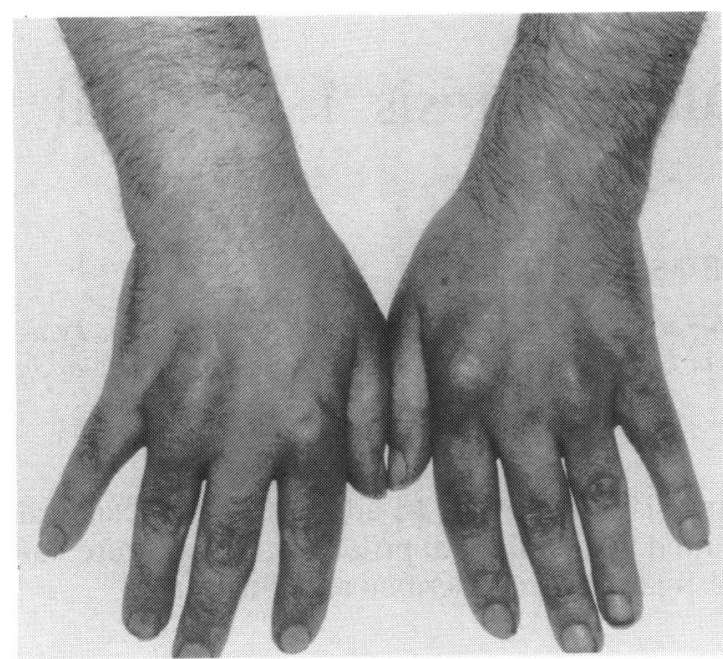

Fig. 2 Brachydactyly with extensor tendon xanthomata of hands.

multiple bulky xanthomata of the extensor tendons, notably on his elbows, hands, and Achilles tendons (Figs. 1, 2). Ophthalmic examination showed best corrected visual acuities of right $2 / 60$ and left $4 / 60$. He had bilateral coronary nuclear and posterior subcapsular cataracts (Fig. 3).

In May 1986 he underwent right extracapsular cataract extraction with insertion of a posterior chamber intraocular lens. He made an uneventful recovery. Best corrected acuity was $6 / 6$ part and the right fundus was normal. In August 1986 the tendon xanthoma on his left elbow was excised. Histological examination showed a tuberose xanthoma.

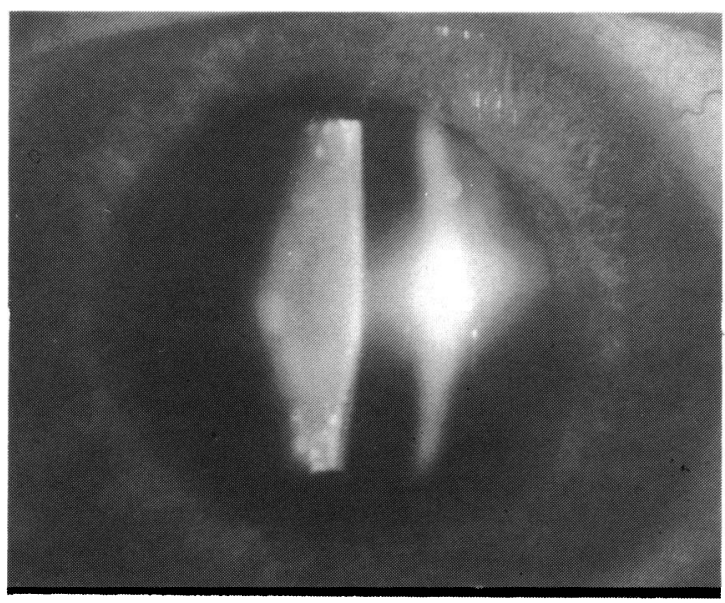

Fig. 3 Slit-lamp photograph of left eye showing coronary and posterior subcapsular lens opacities.

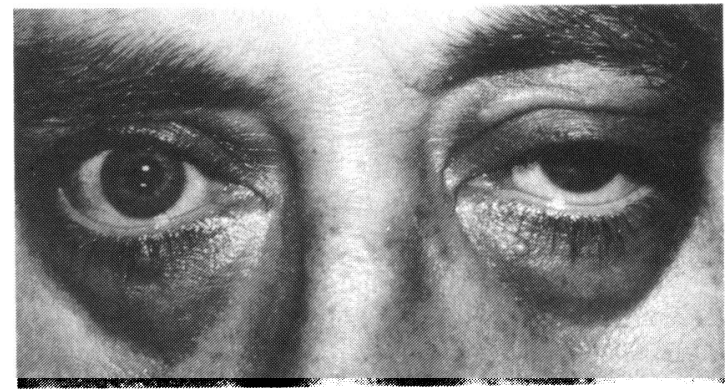

Fig. 4 Left proptosis with mass in upper palpebral sulcus.

In October 1986 he presented with left proptosis. His visual acuities were right $6 / 9$ and left counting fingers. There was a $2 \mathrm{~mm}$ left proptosis with a firm mass palpable in the upper palpebral sulcus (Fig. 4). Pupils and eye movements were normal. A-scan ultrasonography showed a well demarcated lesion close to the superior aspect of the left globe, noncompressible, and of low reflectivity. CT scans of the left orbit revealed a marked concentric thickening of the left levator complex (Figs. 5 a,b,c). Biopsy of the lesion under local anaesthetic showed a typical xanthoma. The proptosis remained unchanged.

In September 1987 he underwent left extracapsular cataract extraction with insertion of a posterior chamber intraocular lens. After the operation his recovery was uneventful, with a best corrected acuity of $6 / 5$. The left fundus was normal. On this occasion the lens anterior capsule, nucleus, and cortical washings were collected and preserved in liquid nitrogen for biochemical analysis.

A year later his visual acuities were $6 / 6$ part right, $6 / 6$ left, and N5 for near vision.

BIOCHEMICAL INVESTIGATIONS AND

TREATMENT

Before treatment was begun serum lipid analysis was performed: The results were: fasting cholesterol $6.1 \mathrm{mmol} / \mathrm{l}$ (reference range $2 \cdot 8-7 \cdot 2$ ); fasting triglycerides $1.6 \mathrm{mmol} / \mathrm{l}(0 \cdot 8-2 \cdot 0)$; HDL-cholesterol 0.9 $\mathrm{mmol} / \mathrm{l}(1 \cdot 0-1 \cdot 5)$; serum cholestanol $93 \mu \mathrm{mol} / \mathrm{l}(<10)$.

The plasma biochemical profile, including liver function tests, was normal. Treatment was begun with ursodeoxycholic acid, increasing gradually to $600 \mathrm{mg}$ per day. After eight months' treatment there had been no measurable change in the size of the xanthomata of the Achilles tendon, though the left proptosis had slightly regressed. The patient admitted poor compliance with therapy. His serial serum cholestanol levels remained elevated. Chenodeoxycholic acid has been shown to lower serum cholestanol levels and reverse neurological dysfunction in $\mathrm{CTX}^{\circ}$ but not xanthomata or cataracts. Our 


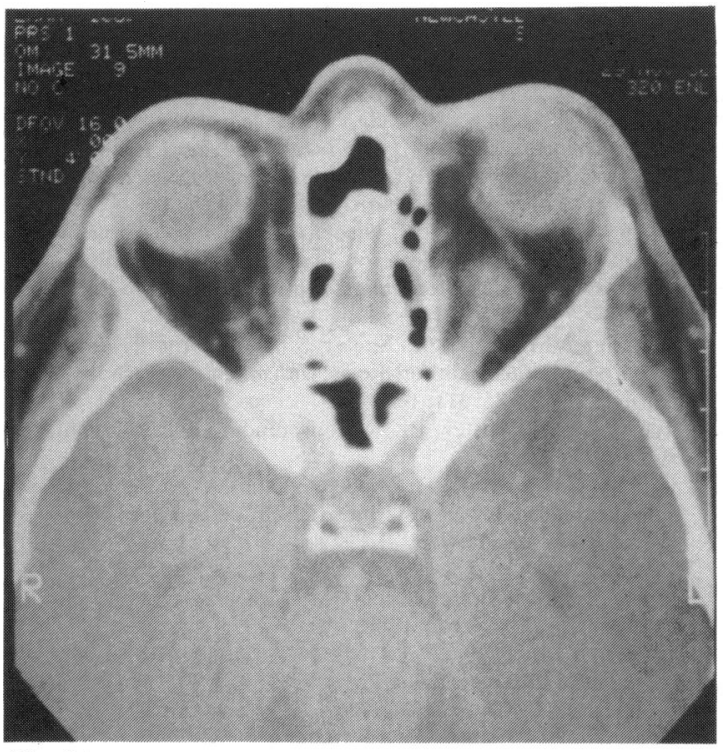

Fig. 5A

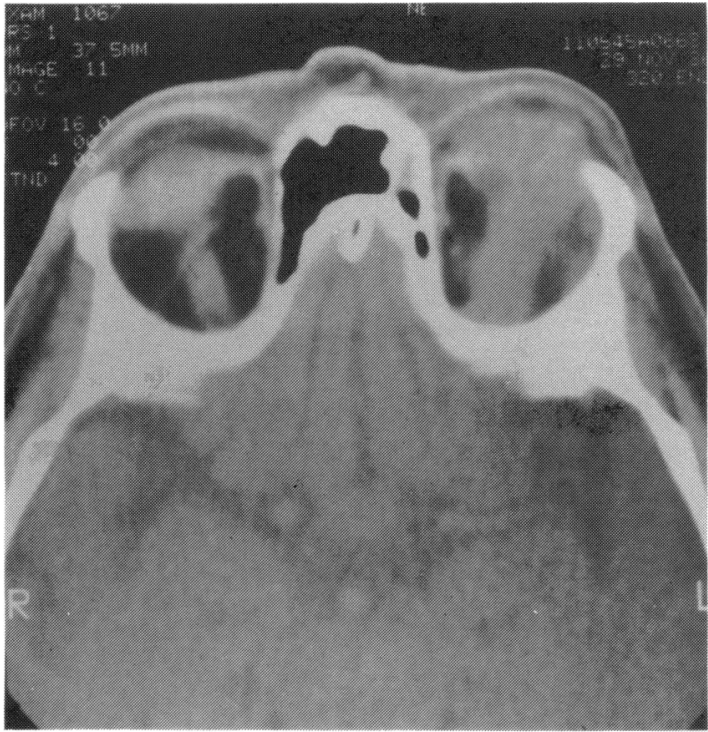

Fig. 5C

Fig. 5 Orbital CT scans showing mass in left levator complex.

patient's treatment has now been appropriately modified.

\section{Discussion}

Our patient shows clinical and biochemical features pathognomonic of CTX.' Cataracts, which may be

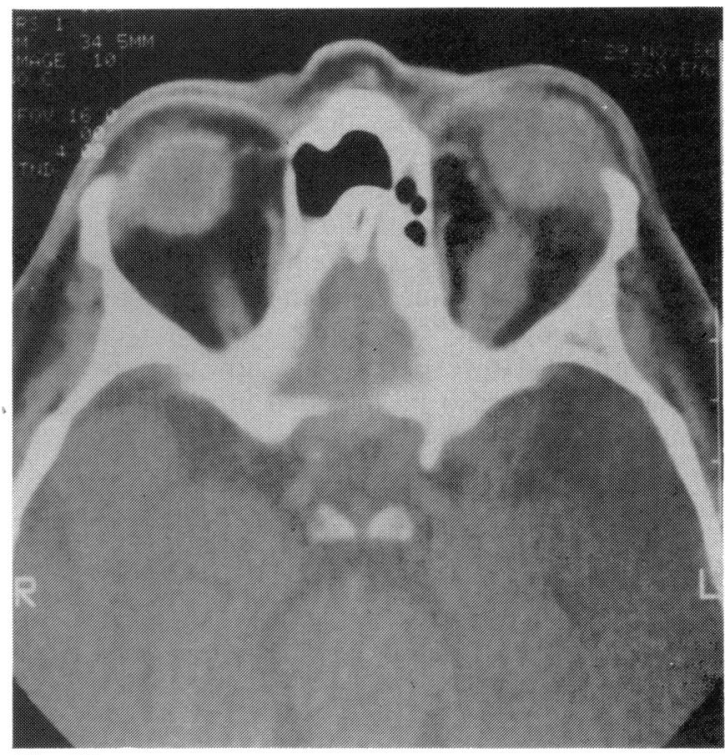

Fig. 5B

seen as early as age $15,,^{1+}$ have been recorded in about $85 \%$ of all reported cases. It is stated that cataract extraction 'by young adulthood' is usually necessary. ' Our patient's late presentation accounts for his relatively advanced age at surgery.

The typical lens opacity is described as 'zonular cortical' and is well illustrated in a recent review.' Our patient's opacities were more advanced than this.

We have found references to only three other ophthalmic complications in CTX, namely, xanthelasma deposition,' an increased content of sterols in the extraocular muscles,' and 'atrophy of the entire optic pathway. ${ }^{4 \times}$ Proptosis, however, is a hitherto undescribed clinical feature. In this case it is due to xanthoma deposition in the extraocular muscles and reflects the generalised tendency to xanthoma deposition, particularly in tendons, which affects the Achilles tendon most frequently but also the tibial tuberosities, triceps, and finger extensors.'

If untreated, CTX leads to an unpleasant early death from relentless neurological deterioration with spasticity, ataxia, bulbar palsy, incontinence, and dementia. ${ }^{+}$Psychiatric disorders may be prominent." Myocardial infarction may occur and has been recorded as young as age 36. 'The prospect of halting or even reversing this decline by treatment with oral bile acid supplements makes it vitally important that this condition be promptly diagnosed.

Treatment with chenodeoxycholic acid is reported to have resulted in a favourable biochemical response, with return of plasma cholestanol levels nearly to normal. " Our patient was initially treated 
with ursodeoxycholic acid because it has a lower reported incidence of gastrointestinal side effects." Failure of the biochemical abnormality to respond to ursodeoxycholic acid has been reported 1112 and is confirmed by our observations.

The mechanism of cataract formation in CTX is of some interest in view of the abnormalities of lipid metabolism in this disease. We have shown that there is a raised level of cholestanol in the cataractous lens in CTX compared with senile cataract (report in preparation). However, we have now demonstrated that CTX must also be included in the differential diagnosis of proptosis.

Our thanks are due to Mr Derek Mitchell, top grade biochemist Department of Chemical Pathology and Metabolic Disorders, St Thomas's Hospital, London, for help with blood lipid analysis, and to $\mathrm{Mr}$ Ken MacLean, medical photographer, Royal Victoria Infirmary and General Hospital, Newcastle upon Tyne, for the clinical photographs. Copyright for the clinical photographs is held by the University of Newcastle upon Tyne.

\section{References}

1 Stanbury JB, Wyngaarden JB, Fredrickson DS, Goldstein JL, Brown MS, eds. The metabolic basis of inherited disease. 5th ed. New York: McGraw Hill, 1984: 714.
2 Salen G. Cholestanol deposition in cerebrotendinous xanthomatosis: a possible mechanism. Ann Intern Med 1971; 75: 843-5.

3 Setoguchi T, Salen G, Tint GS, Mosbach EH. A biochemical abnormality in cerebrotendinous xanthomatosis: impairment of bile acid biosynthesis associated with incomplete degradation of the cholesterol side chain. J Clin Invest 1974; 53: 1393-401.

4 Van Bogaert L, Scherer HJ, Epstein E. Une forme cérébrale de la cholesterinose généralisée. Paris: Masson, 1937.

5 Salen G. Meriwether TW, Nicolau G. Chenodeoxycholic acid inhibits increased cholesterol and cholestanol synthesis in patients with cerebrotendinous xanthomatosis. Biochem Med 1975: 14: 57-74.

6 Berginer VM, Salen G, Shefer S. Long-term treatment of cerebrotendinous xanthomatosis with chenodeoxycholic acid. $N$ Engl J Med 1984; 311: 1649-52.

7 Truswell AS, Pfister PJ. Cerebrotendinous xanthomatosis. Br Med J 1972; i: 353.

8 Guilain G, Bertrand I, Godet-Guillain M. Etude anatomoclinique d'un cas de cholesterinose cérébrale. Rev Neurol (Paris) 1942: 74: 249-63.

9 Berginer VM, Foster NL, Sadowsky M, Townsend JA. Psychiatric disorders in patients with cerebrotendinous xanthomatosis. Am J Psychiatry 1988; 145: 354-7.

10 British National Formulary. No. 13. London: British Medical Association/Pharmaceutical Press. 1987: 67.

11 Waterreus RJ, Koopman BJ. Neurology 1987; 37: 1091.

12 Koopman BJ, Wolthers BG, Van der Molen JC, Waterreus RJ. Bile acid therapies applied to patients suffering from cerebrotendinous xanthomatosis. Clin Chim Acta 1985; 152: 115-22.

Accepted for publication 5 June 1989 